Historic, archived document

Do not assume content reflects current scientific knowledge, policies, or practices. 

$\mathrm{F}>64 \mathrm{~L}$
United States

d) Department of

Agriculture

Forest Service

Intermountain Forest and

Range Experiment Station

Research Paper

INT-269

January 1981

\author{
LARGE-SCALE COLOR AERIAL \\ PHOTOGRAPHY AS A TOOL IN
} SAMPLING FOR MORTALITY RATES

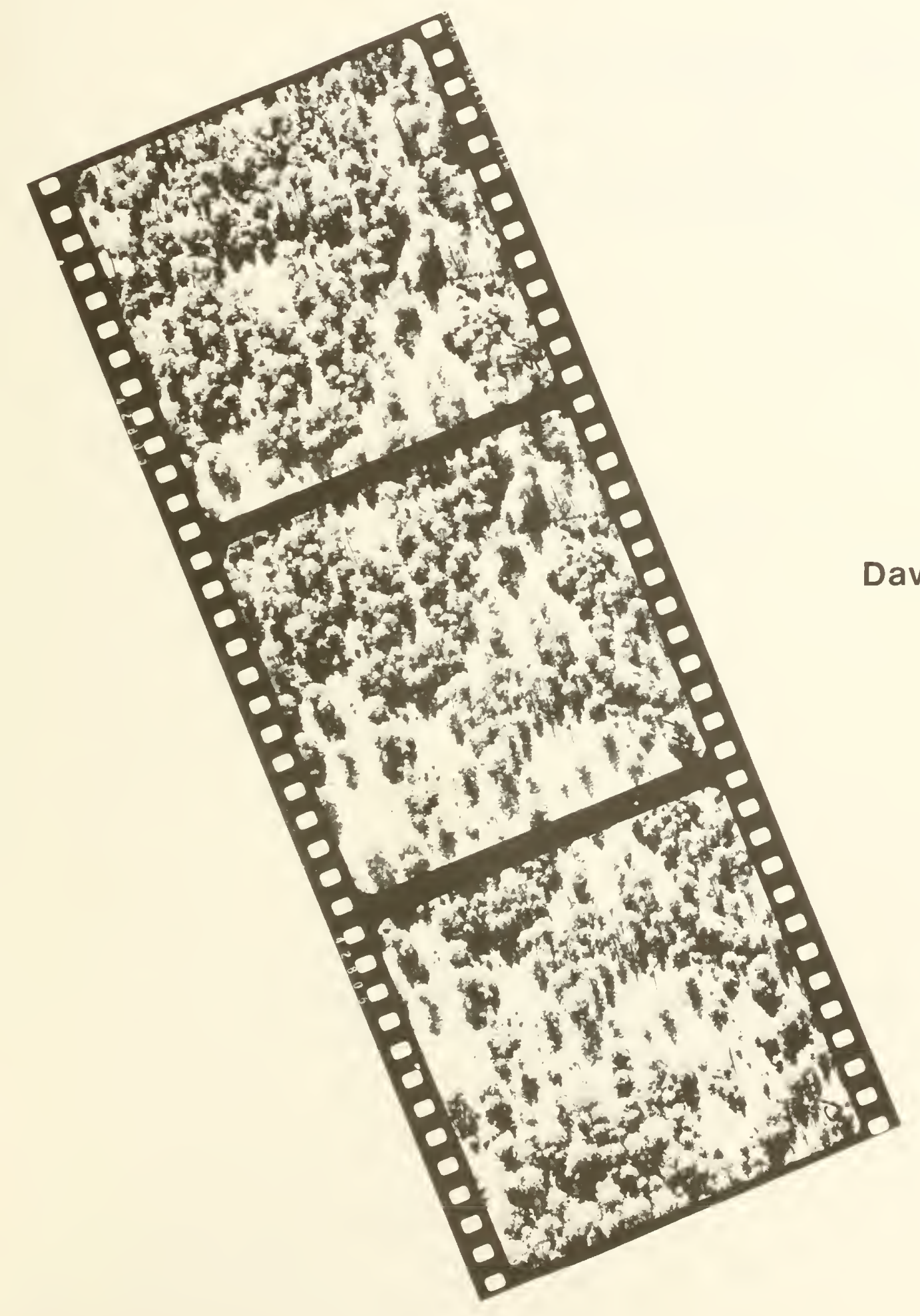



USDA Forest Service

Research Paper INT-269

January 1981

\section{LARGE-SCALE COLOR AERIAL PHOTOGRAPHY AS A TOOL IN SAMPLING FOR MORTALITY RATES}

David A. Hamilton, Jr. 


\section{THE AUTHOR}

DAVID A. HAMILTON, JR., is a research forester working in timber measurements and management planning research at the Forestry Sciences Laboratory, Moscow, Idaho. Since receiving his Ph.D. degree in forestry from lowa State University in 1970, he has worked on the sampling and modeling of forest mortality and on the problem of specifying optimal precision levels for resource inventories. 


\section{RESEARCH SUMMARY}

Mortality rates specify the proportion of trees with a given set of characteristics that are expected to die in a fixed time interval. Knowledge of these rates is the weakest of the key components of yield predictions. This lack of knowledge of mortality rates is primarily due to a lack of suitable data and inappropriate or inefficient data collection procedures. The objectives of this study, stated as questions, are:

1. Can 1-and 2-year-old mortality be accurately identified on large-scale aerial photography?

2. Can species identification of mortality trees and of green trees be accurately done on large-scale aerial photography?

Test results indicate that 1-year mortality can be dated and that, with acceptable accuracy, species can be assigned to green trees and to 1-year mortality trees on 1:1600 and 1:2400 scale color aerial photography. These results have led to the design of a mortality sampling procedure that uses a quarter mile strip ( 8 frames) of $70 \mathrm{~mm}$ true color aerial photography at a scale of 1:2400 as the primary sample unit. At a scale of 1:2400, each frame covers 2.25 times the area covered by a frame at 1:1600. Use of this larger sample unit increases the likelihood of including some mortality on each sample unit. The procedure was designed for the Northern Region, USDA Forest Service.

\section{CONTENTS}

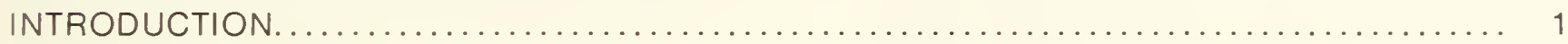

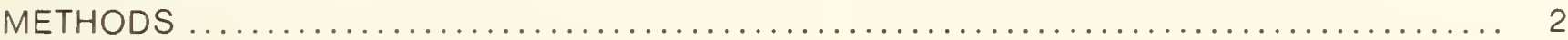

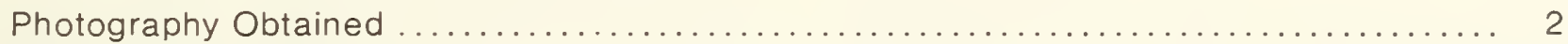

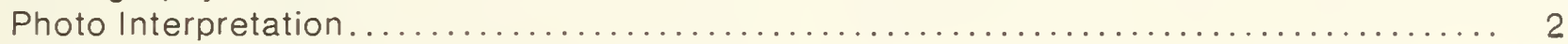

Ground Examination............................................... 2

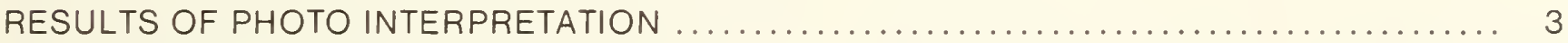

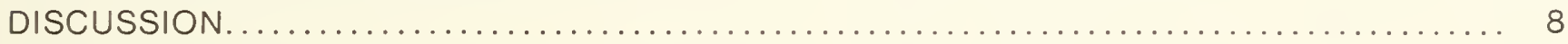

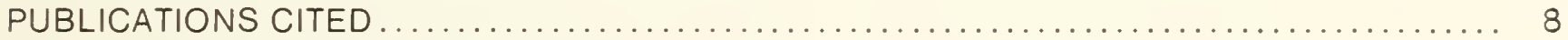





\section{INTRODUCTION}

Mortality rates, diameter increment rates, and height increment rates are the key components of all yield predictions. Mortality rates are the weakest of the three components. Information on diameter and height increment rates is readily available from silvicultural research plots where scientists have studied growth under a wide array of environmental conditions and management strategies. In addition, in most forest survey or management planning inventories, information on current diameter and height increment rates is collected. Where such data are not readily available, diameter and height increment can be observed in a single visit to the plot. Annual rings and nodal scars provide the time scale that makes these measurements possible on many species growing in temperate forests. There is no comparable time scale for easily and accurately postdating mortality. Thus, data describing the occurrence of mortality is more difficult to obtain.

Silvicultural research plots on which individual trees have been measured for many years provide a potential source of data for estimating relationships between stand and tree characteristics and mortality rates. However, use of such data is severely weakened by the common practice of deleting plots containing heavier than average mortality from the experiment. Further, such data are not available for all species and localities and do not provide measures of current levels of mortality.

Many mortality surveys estimate the amount of dead timber in a population by counting dead trees, measuring the volume of dead trees, or measuring the number of acres that contain a substantial number of dead trees. Such information is of little value in predicting future mortality.

Sampling for mortality rates requires two types of information not collected in the usual mortality survey: counts of green trees and the year of death for mortality trees. Mortality rates specify the proportion of trees with a given set of characteristics that are expected to die in a fixed time interval; to know that proportion both green and dead trees must be sampled. It is also necessary to determine a time scale for mortality occurrence; this requires that the time of death be estimated for each dead tree sampled.

Once mortality rates are established, they may be used for many purposes. Current mortality rate models are designed to describe the occurrence of mortality in a stand as the stand grows. However, if an estimate of number of dead trees or an estimate of volume in dead trees is desired, mortality rate models may be used in the context of a stand inventory compilation system to produce these estimates (much as volume equations are used to estimate stand volume).

Management planning inventory information in the Northern Region of the USDA Forest Service is collected on variable radius plots (basal area factor $=40$ ) arranged in a 10 -chain by 5 -chain grid on subcompartments of about 500 acres (200 ha) selected with probability proportional to National Forest acreage (Stage and Alley 1972). Mortality data are collected by estimating which trees have died in the past 5 years on each sample point. The sampling design results in efficient estimates of variables such as volume, diameter, diameter growth rate, and height, but the design is inefficient for collecting information about mortality.

This is true for several reasons. Under normal conditions, mortality is a rare event. A rule of thumb is that the expected normal mortality rate is about 0.5 percent per year (that is, one tree out of every 200 will die in a year's time). Also, mortality is not uniformly distributed over the forest in either time or space. An assumption of some form of clustered distribution for mortality trees is probably more accurate than an assumption of either a uniform or random distribution. Thus, most standard ground inventory systems (either variable radius plot sampling designs or designs using small fixed area plots) are not very efficient for collecting mortality information. Finally, there is some question as to the ability of field crews to accurately estimate which trees have died within the past 5 years. Postdating mortality on trees dead for more than 2 years is difficult even for a trained pathologist or entomologist because of the great variability in deterioration of individual trees (Miller and Keen 1960; Keen 1955). 
Because the distribution of mortality is often clustered and because of the large size of some areas to be inventoried, a sampling design making use of large-scale aerial photography would appear to offer advantages. Heller and others (1964) and Sayn-Wittgenstein (1960) determined that tree species can be identified to acceptable accuracy standards on large-scale color aerial photography. This paper investigates the use of aerial photography in mortality sampling. The study objectives, stated as questions, are:

1. Can 1- and 2-year-old mortality be accurately identified on large-scale aerial photography?

2. Can species identification of mortality trees and of green trees be accurately done on large-scale aerial photography?

\section{METHODS}

\section{Photography Obtained}

For this study, $70 \mathrm{~mm}$ aerial photography was taken with 60 percent endlap on two flight lines on one subcompartment and a single flight line on a second subcompartment of the Coeur d'Alene National Forest (administered as part of the Idaho Panhandle National Forests). The flight lines varied in length from 1.5 miles $(2.4 \mathrm{~km})$ to slightly over 2 miles $(3.2 \mathrm{~km})$. The photographs were taken and processed in June 1971 by John Wear and Richard Myhre, who at the time were with the Remote Sensing Research Work Unit of the Pacific Southwest Forest and Range Experiment Station. The combinations of scale and film type used in this study were $1: 1600$ and $1: 2400$ true color transparencies. However, because the photographs were taken over rough terrain, there is considerable variability in scale in different segments of the photo strips. Because $70 \mathrm{~mm}$ photography at scales of $1: 1600$ and $1: 2400$ frequently does not include a broad enough area to be used to locate specific photo plots on the ground, 1:4800 black and white photographs were taken simultaneously. The 1:4800 black and white photographs were not used in the identification of green or mortality trees. Instead, they were enlarged, printed, and used to locate photo plots for ground examination.

\section{Photo Interpretation}

The subcompartments photographed fell primarily in the grand fir-cedar-hemlock ecosystem. Species growing on the photographed portions of the subcompartments were Douglas-fir, grand fir, white pine, western larch, western hemlock, ponderosa pine, lodgepole pine, and western redcedar. Stand density conditions on the two subcompartments ranged from low density, poorly stocked stands to high density, well stocked stands.

All photo interpretation was done in stereo. On each photo frame all 1- and 2-year mortality trees were identified by species: the 1-year mortality by brightly discolored foliage and retention of most of this foliage; and the 2-year mortality by dully discolored foliage with very little of it retained (Miller and Keen 1960). These characteristics vary both among species and from year to year because of climatic variation. However, these characteristics are an acceptable average descriptor for general use in dating mortality on large-scale aerial photography.

On every 12 th frame of $1: 1600$ scale photography, a 0.6 inch by 0.6 inch $(1.52 \mathrm{~cm}$ by $1.52 \mathrm{~cm})$ subplot was established near the center of the frame. Although this resulted in unequal sized plots on the ground (because of variation on scale on each flight line) it did assure that a constant proportion of the photographs were sampled. A total count of green trees by species was made on each subplot. In addition, five trees were selected on each subplot to test species identification on an individual tree basis.

\section{Ground Examination}

Every sixth frame of $1: 1600$ scale photography was used for ground examination. All 1-and 2-year mortality trees identified on the photographs were checked on the ground. Discrepancies were examined again both on the ground and on the photos in an effort to explain the error and thus improve future photo interpretation.

Each photo subplot used to sample green trees was located on the ground. All green trees on these plots were counted by species. The five 
trees selected on each photo subplot for testing individual tree species identification were located on the ground and the species recorded. Similar methods were applied to the 1:2400 scale photography. However, ground examination was limited to a subset of those areas used to ground check the $1: 1600$ scale photography.

As a further test of accuracy of identifying 1-year mortality trees, in summer 1972, the flight lines on the two subcompartments were reflown by Robert Heller, then with the Pacific Southwest Forest and Range Experiment Station. The photographs were $70 \mathrm{~mm}, 1: 3200$ scale true color transparencies. This scale was selected to provide some assurance that a majority of the 1971 photographs would be included in the 1972 coverage.

\section{RESULTS OF PHOTO INTERPRETATION}

The first study objective deals with the accuracy of identifying 1 - and 2-year mortality trees. Tables 1-4 summarize the accuracy with which date of mortality was assigned to mortality trees.

The results indicate that 1-year mortality trees can be accurately identified on 1:1600 scale color aerial photography. There were errors in identifying and dating white pine mortality on one of the flight lines on the 1:1600 scale photography. This was due to inadequate training of interpreters. Careful examination has led me to conclude that, with proper training, this problem can be avoided.

If white pine are omitted from the analysis, the number of mortality trees correctly dated, expressed as a percent of ground truth, increases from 74 percent to 85 percent (tables 3 and 4). Thus, I anticipate that 1 -year mortality can be correctly dated at least 85 percent of the time on $1: 1600$ scale photography. Interpretation accuracy is reduced to 70 percent when photography scale is reduced to $1: 2400$.
The number of 2-year mortality trees correctly dated, expressed as a percent of ground truth, is only 50 percent on 1:1600 scale photography. When the photo scale is reduced to $1: 2400$, interpretation accuracy decreases to 22 percent.

This reduction in interpretation accuracy is primarily due to an increase in the number of missed trees on the 1:2400 scale photography. If white pine are deleted from the anaiysis virtually no difference exists in the interpreter's ability to identify 1-year mortality on the two photo scales, given the dead tree is detected on the photograph (tables 3 and 4). On 1:1600 scale photography, 88 percent of the trees rated as 1-year mortality trees were correctly rated. On 1:2400 scale photography, 90 percent of the trees rated as 1-year mortality trees were correctly rated.

Tables 1 and 2 may also be used to compare the distribution of mortality trees identified on the aerial photographs with the actual distribution on the ground. On 1:1600 scale photography, the number of 1-year mortality trees is within 2 percent of the number found on the ground. On 1:2400 scale photography, the number of 1-year mortality trees is within 7 percent of the number found on the ground. Thus, the number of errors of omission (1-year mortality trees either missed or misclassified on the photos) must be almost equal to the number of errors of commission (trees identified on the photos as 1-year mortality that actually had either been dead more than 1 year or were not dead).

Interpretation accuracy of 2-year mortality is much poorer. On 1:1600 scale photography the number of 2-year mortality trees identified is only within 25 percent of the number found on the ground. The number of 2-year mortality trees identified on 1:2400 scale photography is only within 50 percent of the number found on the ground. The reduction in interpretation accuracy is due primarily to the many 2-year mortality trees missed on the photographs. Most of the missed 2-year mortality trees were identified as being dead for more than 2 years and thus were not recorded. 
Table 1.-Results of photo interpretation of 1:1600 scale photography for date of mortality

Photo classification

Ground classification

Dead 1 year Dead 2 years

Missed

Total

Dead 1 year

31

1

10

42

Dead 2 years

4

14

10

28

Dead more than 2 years

1

5

6

Not dead or no tree

7

1

8

Total

43

21

20

84

Table 2.-Results of photo interpretation of 1:2400 scale photography for date of mortality

Photo classification

Ground classification

Dead 1 year

Dead 2 years

Missed

Total

Dead 1 year

20

2

7

29

Dead 2 years

2

4

12

18

Dead more than 2 years

3

3

Not dead or no tree

5
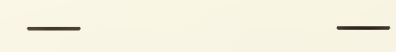

5

Total

27

9

19

55 
Table 3.-Results of photo intrepretation of $1: 1600$ scale photography for date of mortality (excluding white pine)

Photo classification

Ground classification Dead 1 year Dead 2 years Missed Total

$\begin{array}{lcccc}\text { Dead 1 year } & 28 & 1 & 4 & 33 \\ \begin{array}{l}\text { Dead 2 years } \\ \text { Dead more than 2 years }\end{array} & 3 & 14 & 7 & 24 \\ \text { Not dead or no tree } & 1 & 3 & - & 3 \\ \quad \text { Total } & 32 & 18 & 11 & 61\end{array}$

Table 4.-Results of photo interpretation of $1: 2400$ scale photography for date of mortality (excluding white pine)

Photo classification

Ground classification

Dead 1 year Dead 2 years

Missed

Total

Dead 1 year

Dead 2 years

Dead more than 2 years

Not dead or no tree

Total
19

1

1

21

-

\section{2}

4

2

6

27

2

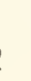

11

16

2

1


The second study objective deals with the interpreter's ability to identify the species of green and mortality trees. Species identification of 1-year and 2-year mortality trees is summarized in tables 5 and 6 . The results indicate that we can identify 1 year mortality by species with reasonable accuracy on either $1: 1600$ or $1: 2400$ scale color aerial photography. However, species identification of 2 year mortality is very poor.

On 1:1600 scale photography, 88 percent of the 1-year mortality trees identified on the photos were assigned the proper species identification. Species was assigned properly to only 44 percent of the 2-year mortality trees. On 1:2400 scale photography, 91 percent of the 1-year mortality trees were properly identified. Species was properly assigned to 83 percent of the 2 -year mortality trees. However, so few 2-year mortality trees were included in the sample that this is probably not a true indication of the interpreter's ability to identify species of 2-year mortality on 1:2400 scale photography.

Green tree species identification has only been tested on 1:1600 scale photography. However, the results of testing the accuracy of species identification of mortality trees indicates that one should expect very little difference in interpreter's ability to identify species on 1:2400 scale photography. Of the 80 green trees selected on the $1: 1600$ scale photos, 95 percent were correctly identified. Thus, it is anticipated that on 1:2400 scale photos properly trained interpreters will also be able to accurately identify the species of close to 95 percent of the green trees.
Table 5.-Species identification of mortality trees on 1:1600 scale photography

\begin{tabular}{lcc}
$\begin{array}{l}\text { Identification } \\
\text { Dead 1 } \\
\text { year }\end{array}$ & $\begin{array}{c}\text { Dead 2 } \\
\text { years }\end{array}$ \\
\hline $\begin{array}{l}\text { Species correctly } \\
\text { identified }\end{array}$ & 28 & 8 \\
$\begin{array}{l}\text { Species incorrectly } \\
\text { identified }\end{array}$ & 4 & 10 \\
$\begin{array}{l}\text { Missed } \\
\text { Total }\end{array}$ & 10 & 10 \\
& 42 & 28 \\
\hline
\end{tabular}

Table 6.-Species identification of mortality trees on 1:2400 scale photography

Identification

Dead 1

Dead 2

year years

Species correctly

20 5

identified

Species incorrectly

2

1

identified

Missed

$\underline{7}$

12

Total

29

18 
Table 7 describes the relationship between the number of green trees counted on the photo subplots and the number counted when these plots were measured on the ground. The photo count of green trees was 16 percent below the ground count. Grand fir and Douglas-fir were the most common species on the photographs. The photo count of grand fir was 88 percent of the ground count. The photo count of Douglas-fir was 82 percent of the ground count. The other species were too poorly represented in the sample to make inferences about the accuracy of the photo counts.
The second-year photo interpretation made use of both the 1971 and 1972 photography. All 1-year and 2-year mortality trees were identified by species on the 1:3200 scale, 1972 photography. Each tree that also appeared on the 1971 photography was located and examined on the 1:1600 true color photography obtained in 1971.

Of the 1-year mortality trees, 89.4 percent were properly identified on the 1:3200 scale photography. All trees identified as 1-year mortality trees on the 1:3200 scale, 1972 photography were alive in 1971. A small number of trees identified as 2year mortality on the 1972 photography were alive in 1971.

Table 7.-Species identification of green trees on 1:1600 scale photography

\begin{tabular}{|c|c|c|c|c|c|c|c|c|c|c|}
\hline \multirow[b]{2}{*}{$\begin{array}{l}\text { Flight } \\
\text { line }\end{array}$} & \multirow[b]{2}{*}{$\begin{array}{l}\text { Source } \\
\text { of data }\end{array}$} & \multicolumn{9}{|c|}{ Species } \\
\hline & & $\begin{array}{c}\text { Grand } \\
\text { fir }\end{array}$ & $\begin{array}{l}\text { Douglas. } \\
\text { fir }\end{array}$ & $\begin{array}{c}\text { - White } \\
\text { pine }\end{array}$ & $\begin{array}{l}\text { Western } \\
\text { hemlock }\end{array}$ & $\begin{array}{l}\text { Western } \\
\text { larch }\end{array}$ & $\begin{array}{l}\text { Western } \\
\text { redcedar }\end{array}$ & $\begin{array}{c}\text { Ponderosa } \\
\text { pine }\end{array}$ & $\begin{array}{l}\text { Lodgepole } \\
\text { pine }\end{array}$ & Total \\
\hline \multirow{2}{*}{1} & Photo count & 48 & 43 & 23 & 6 & 5 & 6 & 4 & - & 135 \\
\hline & Ground count & 57 & 46 & 30 & 8 & 5 & 8 & 5 & - & 159 \\
\hline \multirow{2}{*}{2} & Photo count & 34 & 95 & 1 & 1 & 1 & - & - & 2 & 134 \\
\hline & Ground count & 44 & 113 & 1 & 1 & 1 & - & 1 & 2 & 163 \\
\hline \multirow{2}{*}{3} & Photo count & 52 & 69 & - & 1 & 11 & - & - & 3 & 136 \\
\hline & Ground count & 52 & 92 & - & 1 & 15 & - & - & 3 & 163 \\
\hline \multirow{2}{*}{ TOTAL } & Photo count & 134 & 207 & 24 & 8 & 17 & 6 & 4 & 5 & 405 \\
\hline & Ground count & 153 & 251 & 31 & 10 & 21 & 8 & 6 & 5 & 485 \\
\hline
\end{tabular}




\section{DISCUSSION}

These procedures may not be applied to estimate mortality rates for larch. Larch is deciduous and thus year of mortality cannot be estimated by the foliage retention characteristics described here. Larch killed prior to the time photos are taken but showing no signs of needle discoloration, or trees killed after photos are taken, will drop their needles prior to the next growing season. Such trees will not fit the characteristics of 1-year mortality trees on either current-year photographs or on those taken the following year, and thus will never be counted as mortality trees. Similar problems exist if this approach is applied to other deciduous species. Larch mortality dating is further complicated by the defoliation of larch by larch casebearer. Such trees may be difficult to distinguish from larch that have died during the current growing season.

The description of a dead tree may also impose limitations on the use of these procedures. A tree that has died in the past year is identified by its brightly discolored foliage and by the retention of the majority of this foliage. Trees that die slowly (a few branches each year) will never fall into this category and thus will never be classified as current mortality. This is not a problem unique to photo identification of current mortality. It is difficult to determine when such a tree is to be considered dead, even when the tree is observed on the ground.

In spite of these limitations, I decided that 1-year mortality could be dated and that species could be assigned to green trees and to 1-year mortality trees on 1:1600 and 1:2400 scale photography with acceptable accuracy. A procedure was designed for sampling mortality for the Northern Region that uses a quarter mile strip (eight frames) of $70 \mathrm{~mm}$ true color aerial photography at a 1:2400 scale as the basic sampling unit. This scale was selected for practical reasons. With the plane, camera, and lens available to the Region, 1:2400 was the maximum scale that could be obtained.

Although a reduction in interpretation accuracy occurred when the scale was reduced from
$1: 1600$ to $1: 2400,1$ felt that with proper training of interpreters, the 1:2400 scale would provide acceptable results. The sampling design, estimation procedures, and photo interpretation guidelines are described in detail in two companion publications (Hamilton,' and Croft, Heller, and Hamilton ${ }^{2}$ ).

\section{PUBLICATIONS CITED}

Heller, R. C., G. E. Doverspike, and R. C. Aldrich. 1964. Identification of tree species on large scale panchromatic and color aerial photographs. USDA For. Serv. Agric. Handbook 261 , 17 p. Washington, D.C.

Keen, F. P.

1955. The rate of natural falling of beetle-killed ponderosa pine snags. J. For. 53:720-723.

Miller, J. M., and F. P. Keen.

1960. Biology and control of the western pine beetle. USDA Misc. Publ. 800, 381 p. Washington, D.C.

Sayn-Wittgenstein, L.

1960. Recognition of tree species on air photographs by crown characteristics. Can. Dep. For., For. Res. Div. Tech. Note No. 96, 56 p.

Stage, Albert R., and Jack R. Alley.

1972. An inventory design using stand examinations for planning and programming timber management. USDA For. Serv. Res. Pap. INT126, 17 p. Intermt. For. and Range Exp. Stn., Ogden, Utah.

${ }^{1}$ Hamilton, David A., Jr. 1980. Sampling and estimation of mortality using large scale aerial photography. Review draft. Manuscript on file at Intermountain Forest and Range Experiment Station, Moscow, Idaho, $26 \mathrm{p}$.

${ }^{2}$ Croft, Frank C., Robert C. Heller, and David A. Hamilton, Jr. 1980. How to interpret tree mortality on large scale color aerial photographs. Review draft. Manuscript on file at Intermountain Forest and Range Experiment Station, Moscow, Idaho, $29 \mathrm{p}$. 
Hamilton, David A., Jr.

1980. Large-scale color aerial photography as a tool in sampling for mortality rates. USDA For. Serv. Res. Pap. INT-269, 8 p. Intermt. For. and Range Exp. Stn., Ogden, Utah 84401.

Mortality rates specify the proportion of trees with a given set of characteristics that are expected to die in a fixed time interval. Results indicate that 1-year mortality trees can be dated and species can be assigned to green trees and to 1-year mortality trees with acceptable accuracy on $70 \mathrm{~mm}$ color photography at scales of $1: 1600$ and 1:2400. Attempts to date 2-year mortality trees on either scale photography were unsuccessful.

KEYWORDS: Mortality inventory, $70 \mathrm{~mm}$ aerial photography, mortality rate

Hamilton, David A., Jr.

1980. Large-scale color aerial photography as a tool in sampling for mortality rates. USDA For. Serv. Res. Pap. INT-269, 8 p. Intermt. For. and Range Exp. Stn., Ogden, Utah 84401.

Mortality rates specify the proportion of trees with a given set of characteristics that are expected to die in a fixed time interval. Results indicate that 1-year mortality trees can be dated and species can be assigned to green trees and to 1 -year mortality trees with acceptable accuracy on $70 \mathrm{~mm}$ color photography at scales of $1: 1600$ and $1: 2400$. Attempts to date 2 -year mortality trees on either scale photography were unsuccessful.

KEYWORDS: Mortality inventory, $70 \mathrm{~mm}$ aerial photography, mortality rate 
The Intermountain Station, headquartered in Ogden, Utah, is one of eight regional experiment stations charged with providing scientific knowledge to help resource managers meet human needs and protect forest and range ecosystems.

The Intermountain Station includes the States of Montana, Idaho, Utah, Nevada, and western Wyoming. About 231 million acres, or 85 percent, of the land area in the Station territory are classified as forest and rangeland. These lands include grasslands, deserts, shrublands, alpine areas, and well-stocked forests. They supply fiber for forest industries; minerals for energy and industrial development; and water for domestic and industrial consumption. They also provide recreation opportunities for millions of visitors each year.

Field programs and research work units of the Station are maintained in:

Boise, Idaho

Bozeman, Montana (in cooperation with Montana State University)

Logan, Utah (in cooperation with Utah State University)

Missoula, Montana (in cooperation with the University of Montana)

Moscow, Idaho (in cooperation with the University of Idaho)

Provo, Utah (in cooperation with Brigham Young University)

Reno, Nevada (in cooperation with the University of Nevada)

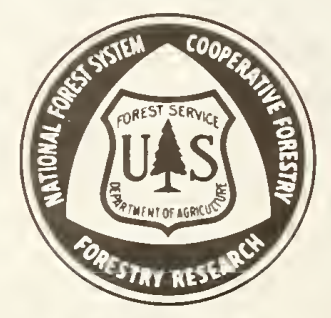

